\title{
Maximising training evaluation for employee performance improvement
}

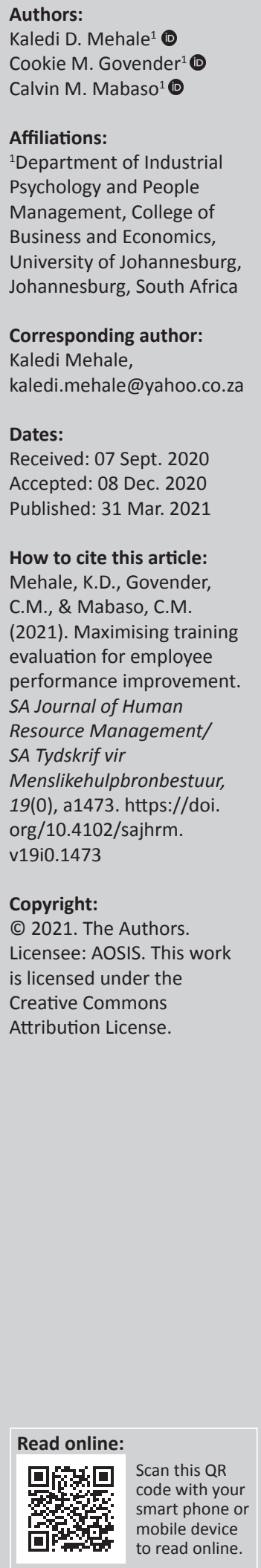

Orientation: Employee performance is a vital aspect within organisations in South Africa (SA). It is argued that poor performance can be addressed through training and development. Performances should be evaluated before and after training interventions to ensure that training was beneficial to the employees.

Research purpose: The study intended to establish whether training evaluation conducted after training in the SA financial sector measures employee performance improvement.

Motivation for the study: Most businesses invest in training and development interventions anticipating that employees will use what they have learned to improve their performance. There is limited recent empirical research on SA financial sector training evaluation tools, especially those that indicate employee performance improvement after training.

Main findings and discussion: The findings of this study indicate the following: SA financial organisations frequently use levels 1-3 (satisfaction; learning; application) of the KirkpatrickPhillips training evaluation tool; continuous employee performance improvement needs to be assessed more regularly, especially after training; and levels $4-5$ (results; ROI) of the Kirkpatrick-Phillips evaluation model are seldom measured due to a lack of skills, motivation, and resources.

Implications and contribution: There are significant implications for Human Resource Development (HRD) professionals and managers within the SA financial sector. Since there is a positive significant association with training evaluation and employee performance, relevant stakeholders must be aware that the purpose of training must be to improve and measure employee performance. This paper contributes theoretically to HRD management practices, training evaluations, and performance improvement. The practical contribution is the proposed Training Evaluation Framework for Performance Improvement for stakeholders to use to ensure that HRD evaluations measures performance improvement.

Keywords: human resource development; training evaluation tools; performance improvement; Kirkpatrick-Phillips; evaluation framework; return on investment.

\section{Introduction}

South African organisations have experienced tremendous challenges, changes and improvements since the country's new democracy, 25 years ago. Political and socio-economic changes necessitated the continuous training and development of employees so that they may be competent and have skills that are aligned with the organisational transformations that occurred. Employee performance must be improved and transformed as it is important in the execution of organisational strategy and the achievement of business strategic objectives (Imran \& Tanveer, 2015). Training increases the knowledge, skills and abilities of the employees (Almohaimmeed, 2017). Managers need to have one-on-one sessions with employees before training interventions to undertake the following: discussing the benefits of attending the training, setting goals for learning and applying what they learn to improve job performance (Imran \& Tanveer, 2015). Employees are more likely to learn and benefit from the training when they are motivated to learn, when they perceive the work environment as supportive to their learning and when they are able to use their newly acquired knowledge and skills on the job (Elnaga \& Imran, 2013).

Skill development is crucial within financial organisations to ensure that employees perform their tasks at the level that the job requires (Elnaga \& Imran, 2013). Effective training enables employees to execute job responsibilities that were difficult prior to training (Hameed \& Waheed, 2011). Human resource development (HRD) professionals and line managers have a responsibility to 
work collaboratively to design, deliver and evaluate training and development interventions which will increase the knowledge, skills and attitude of the employees (Khan, Khan, \& Khan, 2011). There is also a need for managers to use training evaluations to ascertain whether the employees could impart newly acquired knowledge to his or her team members, and whether the organisation's money was well spent (MburuMaina \& Waithaka, 2017). There is a degree of ambiguity on whether HRD professionals and line managers are measuring the employee performance improvement through training evaluation, especially within financial organisations in South Africa (SA).

Previous research reveals that most managers are only assessing the learner's reaction and the learning that occurs during the training intervention (Yusoff et al., 2016). What is not clear, however, is whether managers and HRD professionals are measuring the application and implementation of training to improve employee performance. Lack of support, resources, time and cost associated with training evaluation, and the lack of expertise on the part of HRD professionals, are the main reasons for not evaluating training at high levels that reveal the impact of HRD on business results (MburuMaina \& Waithaka, 2017). Human resource development professionals and managers must calculate training return on investment (ROI) to ensure that it has positive impact on achieving business objectives and strategy (Mara \& Govender, 2017). This article focuses on maximising training evaluation tools, measuring training effectiveness and impact on performance, use of the Kirkpatrick-Phillips five levels of evaluation and the relationship between training evaluation and improved employee performance.

The purpose of the empirical study was to identify whether training evaluation reveals employee performance improvement after training interventions. The research objectives of this study were to identify the training evaluation tools used to evaluate the transfer of learning and to examine business benefits associated with measuring employee performance improvement after training interventions.

This article contributes to research and practice. On a research level, the article contributes to the use of the qualitative semistructured interview method and thematic analysis to correlate employee performance improvement with training evaluation tools. On a practical level, the proposed training evaluation framework for performance improvement encourages HRD professionals, line managers and employees to view training and development as investment opportunities that can benefit business strategy, rather than as a costly and burdensome budget item. The article consists of a literature review, research method, findings, discussion, limitations and conclusion.

\section{Literature review}

The literature review is presented under the following topics: employee performance; importance of training intervention in enhancing performance; training evaluation;
Kirkpatrick-Phillips training evaluation tool and linking training evaluation for performance improvement.

\section{Employee performance}

Employees are the most important asset, resource and building blocks of an organisation (Imran \& Tanveer, 2015). The success or failure of the organisation depends on the performance of employees (Hameed \& Waheed, 2011). Improved performance is vital for most organisations; hence, managers devise strategies to improve performance and measure it from time to time (Imran \& Tanveer, 2015). It is important for HRD professionals and line managers to answer five of these questions: What skills do our employees possess? What skills are needed for the future? Can our employees develop their skills? How can employees receive the appropriate training? Does employee performance improve after training? The answers to these questions are vital to the employee and organisational success, as innovative job performance is stimulated by personal motivation, awareness and ownership of the job role and responsibilities (Hailesilasie, 2009).

Khan et al. (2011) confirm that organisational performance can be stimulated by training and learning opportunities; therefore, when organisations are facing challenges, they need to put more focus on improving employee performance (Ahmed, Rehman, Asad, Hussain, \& Bilal, 2013). Performance deficiency can be overcome by implementing relevant training interventions (Elnaga \& Imran, 2013). The performance gap can be closed by effective leadership, communication, employee development, tolerance to change, procedural justice and organisational culture (Ahmed et al., 2013). There is a positive relationship between training and organisational performance (Aragón, Jiménez, \& Valle, 2014). High performing organisations emphasise these features: firstly, efficacy which is more focused on attracting and retaining talent; secondly, quality which focuses on sharing excellent practices (these organisations, therefore, tolerate poor performance on a minimal level); thirdly, innovation, characterised by originality, promotion of entrepreneurship and taking initiative; fourthly, customer service which is the belief in training employees so that they have a strong relationship with customers and finally branding and marketing, where the organisation focuses on building strong teams and partnerships with a shared and winning mentality (Jesuthasan, 2013).

\section{Importance of training intervention in enhancing performance}

Human resource development involves implementing planned training and development interventions which teaches, instils and modifies competencies, attitudes, belief, knowledge, skills and behaviour through new learning experiences (Aragón et al., 2014). Employees need to continually learn new skills, how to use new tools and systems and stay abreast of technology just to keep up and 
meet job demands (Hameed \& Waheed, 2011). Optimal performance can be reached through employee training such as skills and technical training, management of development and employee orientation programmes (Elnaga \& Imran, 2013). Skills and technical training focus on achieving optimal performance, either because there is a performance gap or because there is a need for employee retraining because of technical changes (Shaheen \& Khan, 2013). Special training and development issues include, amongst others, organisation-wide competency needs, such as employee health, safety, wellness, cultural diversity and multicultural sensitivity (Aragón et al., 2014).

Effective training should be threefold: involve a learning experience, be a planned learning activity and be designed in response to identified needs, in order to be effective (Shaheen \& Khan, 2013). Studies confirm that training is a good way to improve employee skills, knowledge and development opportunities (Sherwani \& Mohammed, 2015). Research reveals that training has a positive impact on employee performance (Elnaga \& Imran, 2013); however, training will not be effective until the individual employee is fully motivated to attend. Employees, who are willing to learn, readily participate in activities such as seminars, workshops, on-the-job and off-the-job training (Hameed \& Waheed, 2011). Training evaluation models justify that the effectiveness of training can be measured when individuals are motivated to use acquired knowledge and skills within the workplace to achieve organisational objectives (Tai, 2004). Training sessions assigned by management tend to lead to higher employee motivation than those where attendance is optional.

\section{Training evaluation}

Training programmes within financial organisations in SA are evaluated for various reasons. Training evaluation plays a crucial role in providing feedback regarding how a specific training programme was offered (Chan, 2016). The purpose of a training evaluation is to determine whether the learners have acquired the new skills and knowledge as a result of implementing the training intervention. It is a process to determine whether the design and delivery of the training programme have been met (Shaheen et al., 2013). Training evaluation is also a systematic process of measuring the quality of a training programme in terms of effectiveness to the organisation's bottom line and how well the training is designed, delivered and managed (Meyer, Opperman, \& Dyrbye, 2003). According to Short (2009), training evaluation should happen at different times as follows: before the training intervention (diagnostic evaluation); during the training intervention (formative evaluation); at the end of the training intervention (summative evaluation) and after the training intervention (longitudinal evaluation).

Once training is completed, employees return to their jobs hoping that they will perform effectively and get promoted. Effective training evaluations should provide useful feedback to relevant stakeholders as follows: training facilitators, participants/learners, management, government, professionals and other relevant parties (Chan, 2016). Training evaluations can cascade into evaluations of the whole organisation, which should be linked to the measurement of the organisational performance (Meyer et al., 2003). Training evaluation is vital because it provides feedback that can be used to improve planned training, measure whether performance improved and whether there was a ROI. Evaluations can be efficient in meeting current business needs by solving past performance challenges and anticipating future opportunities for performance improvement. Furthermore, evaluations are useful tools for the following reasons: providing an indication of various problems, including the lack of individual skills and knowledge; indicating the results of training activities and demonstrating efficacy; and providing clarity on what needs to be improved and what help is required for future additional plans of action (Sharma \& Kurukshetra, 2012).

\section{Kirkpatrick-Phillips training evaluation tool}

The Kirkpatrick-Phillips training evaluation tool has a major impact on evaluation practices in most countries across the globe. In organisations that use this tool, most evaluation processes only focus on measuring level one (reaction), level two (learning) and level three (learner behaviour) and neglect level four (impact) and level five (ROI) measurements because of a lack of knowledge and motivation (Jasson \& Govender, 2017). According to Phillips and Phillips (2009), ROI measures the return on the invested capital, indicating whether training costs paid off in improved employee and organisational performance and profits. The five levels of the Kirkpatrick-Phillips training evaluation model are presented in Table 1.

TABLE 1: The Kirkpatrick-Phillips training evaluation model.

\begin{tabular}{ll}
\hline Level & Description \\
\hline $\begin{array}{l}\text { 1. Reaction, satisfaction and planned action } \\
\text { 2. Learning }\end{array}$ & $\begin{array}{l}\text { Measures whether the participants reacted favourably to the training intervention. } \\
\text { Measures whether trainees acquired the intended knowledge, skills or attributes based on their participation in the training } \\
\text { intervention. }\end{array}$ \\
$\begin{array}{ll}\text { 3. Job application } & \text { Measures the extent to which trainees apply learning and change behaviour in jobs. Conducted immediately after and several } \\
\text { months after the training. }\end{array}$ \\
$\begin{array}{ll}\text { Measures the impact of training on business and environment, as a result of improved employee performance. } \\
\text { 5. Return on investment (ROI) }\end{array}$ \\
$\begin{array}{l}\text { Measures the financial benefits and value of training compared with its costs. Return on investment is stated in percentage, as } \\
\text { high (beneficial) or low (costly). }\end{array}$ \\
\hline Source: Adapted from Curado, C., \& Teixeira, S.M. (2014). Training evaluation levels and ROI: The case of a small logistics company. European Journal of Training and Development, 38(9), 845-870.
\end{tabular}

Source: Adapted from Curado, C., \& Teixeira,
https://doi.org/10.1108/EJTD-05-2014-0037 
Level 1, reaction, is concerned with whether the training programme is aligned to the learners' needs. This stage of evaluation should focus on the training content, programme structure, format, instructional techniques, facilitator's abilities, training style and the quality of the learning environment. The trainees are asked to complete an evaluation questionnaire immediately after the training intervention to measure this level (Meyer et al., 2003).

Level 2, learning, is the stage of the evaluation that focuses on whether learners understood and absorbed the knowledge, principles and skills taught. The trainees should be assessed before and after the training intervention to obtain an accurate picture of what was learned (Ramiah, 2014).

Level 3, job application, focuses on how the trainee's behaviour changes when they return to the work environment after training (Ramiah, 2014). Applying new learning to old jobs must be supportive. Supportive learning application includes these elements: the desire to change; know what to do and how to do it; having the right climate and supportive learning conditions; ongoing reinforcement and monitoring; support in applying new learning in the workplace; learning achievement should be consistently assessed and learning transfer feedback should be provided (Kirkpatrick \& Kirkpatrick, 2013). Post-training performance appraisals should be conducted after several months so that the trainees can be given an opportunity to practise what they have learned and to measure whether training improved performance (Meyer et al., 2003).

Level 4, business results, the results can be measured by assessing whether organisational goals or objectives have been achieved. This stage of evaluation focuses on assessing the changes in variables such as reduced turnover, reduced costs, improved efficiency, reduction in grievances and increase in quality and quantity of production (Ramiah, 2014).

Level 5, ROI, is the process whereby the monetary benefits that are obtained by the organisation over a period, in return, for the financial and other investment in training programmes are measured and calculated (Meyer et al., 2003). Most HRD professionals acknowledge that they must show a high training ROI, so that they can maintain training funds and enhance their human resources status. Admittedly, the calculation of ROI is a very comprehensive part of the evaluation process (Phillips \& Phillips, 2009).

Use of the Kirkpatrick-Phillips training evaluation tool requires a good evaluation plan, where the planner focuses on these six major tasks: development of a systematic evaluation approach; the use of informal and unplanned evaluation opportunities; type of evaluation tool to be used; determine the techniques on how evaluation of data should be collected; how data will be analysed and what judgement should be made regarding the training evaluation (Ramiah, 2014). Most evaluation processes only measure criteria in level 1 and level 2 to assess the trainee's reaction and learning during the learning intervention (Yusoff et al., 2016). Level 3 is moderately used to assess whether training was transferred to job performance, whilst level 4 , the results level, is the most critical and challenging stage of the evaluation process (Kirkpatrick \& Kirkpatrick, 2013). Level 5, ROI measurement, is ignored by most organisations, as training facilitators find this evaluation phase the most difficult. Trainers are unable to assess the results and then compare their findings to the costs of planning, delivering and evaluating the training programme.

Training or learning outcomes should be evaluated using predesigned evaluation techniques. Training evaluations indicate to HRD professionals, managers and the organisation on whether the training intervention was effective and beneficial to the employees (Yusoff et al., 2016). Training programmes are evaluated to establish whether the trainees are transferring what they have learned to the work environment and whether there was any performance improvement after training. Therefore, the evaluation of training programmes is essential to the achievement of the business objectives.

\section{Linking training evaluation to performance improvement}

Organisations implement training programmes to gain real returns on the company's investments (Phillips \& Phillips, 2009). The most challenging aspect of managing the implementation of HRD strategies is to accurately evaluate whether employee behaviour and performance improved after a training intervention (Almohaimmeed, 2017). Training evaluation tools inform HRD professionals whether there was an increase in employee performance as expected (Ramiah, 2014). It is the responsibility of the line manager to identify factors that can have a negative impact on the training programme and take steps to neutralise their effect on job performance (Elnaga \& Imran, 2013).

A good evaluation gives useful information to different stakeholders, namely, training providers, trainees/employees, management and other stakeholders (Chan, 2016). The literature suggests that training should be planned to have a positive effect on performance (Aragón et al., 2014). Whilst some researchers such as Shwerani and Mohammed (2015) suggest that there is a positive relationship between training and performance, other researchers indicate that training has an indirect effect on employee performance and other organisational outcomes (Tshukudu \& Nel, 2015). Previous researchers have asserted that training evaluation must inform whether the training programme has been able to deliver its objectives (Ramiah, 2014). The South African government and non-government agencies have been outsourcing evaluation studies in the past. Currently, all South African government departments have established their own evaluation units. There has been an increase in the number, scope and quality of evaluations conducted in SA recently (Abrahams, 2015). In the South African financial sector, training has generated performance improvement via the development of employee knowledge, skills, ability, competencies and behaviour in the banking industry (Imran \& Tanveer, 2015). 


\section{Research method Research design}

Qualitative research was used to promoting a deep understanding of a natural setting, where human behaviour and events occur (Creswell, 2014). In this study, face-to-face semi-structured interviews were conducted to collect data. Semi-structured interviews also allowed the overall direction to be shaped by the participants' view and experience.

\section{Sample and participants}

The research population consisted of two South African financial organisations. Non-probability sampling was used in this study. Sampling in qualitative research is defined as the selection of specific sources from which data are gathered to address the research objectives (Gentles, Charles, Ploeg, \& McKibbon, 2015). Purposive sampling was appropriate for the study in that professional judgement was used instead of randomly selecting organisations and participants (Creswell, 2014). The researcher selected subject experts about the topic being studied, as well as in gathering detailed in-depth information.

Purposive sampling is a non-random strategy that does not need a set number of participants (Etikan, Musa, \& Alkassim, 2016). The researcher, therefore, decided to select a few people who were willing to provide the information by virtue of experience (Bernard, 2002) because purposive sampling selects information-rich cases for in-depth study (Gentles et al., 2015). It involves the identification and selection of participants who are well informed with the study topic (Creswell, 2014). Participants in this study were willing to share their experiences and opinions in a reflective manner. A total of 12 interviews were conducted. Participants included two HRD professionals, four managers, two training providers, two performance management specialist and two employees/trainees.

\section{Instrument}

This research study used the semi-structured interview as the instrument for data collection. A semi-structured interview is organised around topics that guide to ensure that points of interest are detailed and completed satisfactorily during the interview (Mason, 2002). The aim was to achieve answers or responses to the research questions to achieve the research objectives. The researcher conducted one-on-one discussions with participants to understand whether employee performance improvement was measured using training evaluations. Semi-structured interviews also allowed the researcher to have control over the line of questions to be explored (Creswell, 2014).

The interview was supported by an interview guide that included the pertinent secondary questions derived from this primary research question: Can employee performance improvement be revealed through training evaluation? The interview guide also stipulated the study ethical considerations and request for participant consent (Mason, 2002). Semistructured interviews allowed the overall direction of the study to be shaped by the participants' views, experiences and narratives. The interviews enabled qualitative data collection efficiently and cost-effectively (O'Keeffe, Buytaert, Mijic, Brozovic, \& Sinha, 2016). Whilst the semi-structured interviews provided an opportunity to gather previously unknown information, they were time-consuming, labour-intensive and required interviewer expertise (O'Keeffe et al., 2016).

\section{Procedure}

Data were gathered from existing networks, by sending emails calling for participants willing to provide the relevant information. Initial contact with participants was made by telephone to explain the purpose of the study and the procedure for participants during the interviews. One-onone interviews were held face-to-face. During the interviews, the participants were asked to consent to being recorded to improve the authenticity, accuracy, reliability and validity of the data gathering process. The interview guide was used to ensure that the same questions were asked, the same topics were addressed, in the same way, in every interview (Blumberg et al., 2014).

\section{Data collection}

Data recording ensures that information collected during the interview is captured and available at a later stage for more accurate interpretation (Creswell \& Creswell, 2018). Participants consented to the interview and recording by means of a digital voice recorder. This ensured transparency and improved the quality of the research study. Field notes were also recorded during the interviews. Field notes assisted the researchers in reflecting on collected data and on the data analysis process. Eye contact and observation during the interviews assured participants that the researcher was listening attentively and showed respect and empathy. The researcher was paraphrasing what has been said by the participants to ensure that the participants were adequately understood.

\section{Data analysis}

Thematic analysis was used to analyse the transcribed data. Thematic analysis involves identifying, analysing and interpreting similar experiences within the qualitative data. The flexibility of thematic analysis allowed the use of inductive reasoning that has a potential to provide rich, detailed and complex analysis (Clarke \& Braun, 2013). Inductive analysis allowed for back and forth interpretations between the themes and the database until a comprehensive set of themes and subthemes is established (Creswell \& Creswell, 2018).

\section{Quality of data}

The study is grounded in the fact that both the researchers and readers needed to trust the research findings presented (Thomas \& Magilvy, 2011). The researcher was paraphrasing what has been said by the participants to ensure that the participants were adequately understood. This information 
was recorded to ensure the validity of responses. The concepts of data credibility, dependability, transferability and conformability were applied in addressing issues of trustworthiness in this study. Gathered data and transcripts were always password protected and were only available to the researchers.

\section{Ethical considerations}

Ethical considerations are essential if the research involves human beings (Mouton, 2001). The research methodology was discussed and accepted by all participants, and hence the study was conducted in a responsible way (Blumberg, Cooper, \& Schindler, 2014). These ethical guidelines were adhered to, thus ensuring that the rights of participants were protected: explaining the purpose of the study to the participants; obtaining informed participant consent and assuring participants that their identities will remain anonymous (Blumberg et al., 2014).

\section{Findings}

The following themes emerged from the interviews conducted. The themes arising from the semi-structured interview analysis are presented in line with the research objectives to understand whether employee performance can be improved through training evaluation within financial organisations in SA. The themes arise from 12 interview transcripts as all 12 participants selected for this study participated in the study. This amounts to a $100 \%$ participant response rate. Themes were extracted from coded participant transcripts. The subthemes were derived from the common codes for each theme. Five main themes and their subthemes are presented as the study findings.

\section{Theme 1: Performance improvement through training evaluation tools}

Nine participants $(75 \%)$ indicated that managers need to select appropriate training options to achieve a desired level of performance. They further explained that training delegates should be monitored and evaluated to ensure that they are applying what they have learnt from the training. Other participants believe that training is unnecessary and time-consuming if there is no motivation to apply learnt skills and knowledge effectively.

Subtheme 1.1: Pre- and post-assessment z: Participants were asked how training evaluation was used to assess employee performance before and after training interventions. This was to establish whether financial organisations were using training evaluation tools to assess employee performance before training interventions and to establish how managers valued the frequency of feedback on employee performance in their respective divisions so that they can identify employee training gaps. Two participants $(17 \%)$ confirmed that they were using a training evaluation tool to assess employee knowledge and performance before training interventions. The responses from the participants are indicated as follows:
'As the training provider, I hand out a training evaluation tool to assess the knowledge and performance level of the training delegates before the training intervention. I even give them a chance to discuss their knowledge and expectations from the training.' (Participant 2, female, 45 years)

'I always evaluate the delegates before training intervention to ensure that I understand their skill and knowledge level before training.' (Participant 1, female, 39 years)

Seven participants (58\%) indicated that regular performance improvement feedback to employees should be done on a frequent basis at one-on-one meetings to ensure that they understand what is expected from them in the workplace and to explain the organisational strategic objectives. Responses from participants on the frequency of the performance improvement feedback from managers were indicated by the following verbatim statements:

'I am assessing my team performance improvement through training evaluation once a year in order to provide Learning and Development Department with my employees training needs. I feel that my method is not effective as it does not give me accurate information on whether the previous training has helped in improving employee performance. In terms of performance review, I normally have one-on-one sessions with my team every 3 months to review their performance.' (Participant 10, female, 47, years)

'Our supervisor just rates us during the midyear and final performance review. I feel that she should be assessing us every 3 months so that we can identify if there is any performance gap and request another training intervention if needed.' (Participant 6 , female, 27 years)

The participants also indicated that there was no consistency on how often performance reviews should be conducted within various departments within financial organisations. This suggests that performance reviews vary from one manager to another. This then presents a challenge for measuring whether training interventions have helped to improve performance or even to indicate if there is a training gap. In contrast, one of the participants highlighted that training evaluation is not supposed to assess performance improvement. The participant's comment below suggests that there is no direct relationship between training evaluation and performance improvement:

'The evaluation tool is merely assessing the training intervention and not the learner performance development.' (Participant 4 , female, 55 years)

\section{Theme 2: The training evaluation tool used}

Participants were asked to identify the evaluation tool which they were currently using to evaluate training intervention effectiveness. This was to establish if participants were using a specific evaluation tool to assess performance improvement. Six participants (50\%) indicated that they were using the Kirkpatrick-Phillips training evaluation tool to assess whether employee performance had improved. The other six participants $(50 \%)$ explained that they were using different tools to evaluate whether employee performance had improved after HRD/training interventions. 
Subtheme 2.1: Kirkpatrick-Phillips training evaluation tool: The participants were then asked how they used the Kirkpatrick-Phillips evaluation tool to detect whether improved performance was noted. This determined which levels of the Kirkpatrick-Phillips evaluation tool they were using to assess performance improvement after training interventions. Participants indicated that they used evaluation processes only to measure criteria in levels one, two and three of the evaluation tool. Three participants (25\%) indicated that they were using the Kirkpatrick-Phillips evaluation tool to assess the participants' favourable reactions to the training intervention, if learners acquired the intended knowledge, skills or attributes based on their participation in the training intervention and if they then demonstrated behavioural change after training interventions.

Two participants (17\%) indicated that they used the Kirkpatrick-Phillips training evaluation tool to determine the extent to which the employee applied the learned behaviour or knowledge after they have attended the training. They also indicated that they would like to determine the effect of training interventions on the business. They were interested in what resulted from the improved performance of the learner but did not know how to effectively measure that. Participants' responses are presented as follows:

'I am using Kirkpatrick-Phillips level 1 and 2 to assess the reaction of learners' towards the training and whether the learners have acquired intended knowledge.' (Participant 2, female, 45 years)

'We use Kirkpatrick-Phillips as it is simple and basic - for lack of a better word. It is an effective tool for us as an organisation because of the large volumes of training interventions held across various departments. It also allows us to measure transfer and application of knowledge and skills.' (Participant 5, female, 38 years)

The participants further indicated that some employees in the financial sector believe that evaluation tools should only be used to assess whether the training programme is linked to the learner's needs.

\section{Theme 3: Relationship between training and employee performance}

The participants were asked to explain how the current training evaluation model assesses whether employee performance has improved after training interventions. The aim of this question was to understand whether line managers, performance managers, HRD professionals, training providers and employees within financial organisations in SA are benefitting from linking, using and respecting training evaluation as an effective management tool to reveal performance improvement after training interventions.

Participants' responses indicated that there was a relationship between training and employee performance. Relevant training interventions should be implemented for the sake of developing employee skills and enhancing employee performances. Nine participants $(75 \%)$ indicated that training interventions were improving employee skills, knowledge and productivity. Seven participants (58\%) also mentioned that they noticed employee behavioural changes after training intervention. Two participants (17\%) indicated that employees who attend training tend to be motivated to do their work and perform their work longer than those who do not.

Subtheme 3.1: Employee skills and knowledge improvement: The participants were asked about the extent to which the training impacted on employee skills and knowledge. The participants confirmed that training is a good way to improve employee knowledge, skills and development opportunities. Nine participants (75\%) indicated that training influences the improvement of employee skills and knowledge which leads to better employee performance. Six participants (50\%) stressed that employee knowledge, skills and attitudes should be evaluated before training interventions to ensure that the correct interventions are used. The participants also mentioned that they should be allowed to evaluate themselves before and after training, as this will encourage them to apply what they have learned from training. Some responses of the participants are presented as follows:

'A detailed analysis of the necessary skills for the individual or team must be identified to ensure that the right intervention is used, reviewed, applied and assessed for improved performance.' (Participant 4, female, 55 years)

'We are conducting training needs analysis to determine the type of training required to improve employee knowledge, skills and performance. Most of our soft skills training are assisting in behaviour improvement.' (Participant 10, female, 40 years)

\section{Theme 4: Organisational benefits from training intervention}

A question was posed to explore the business benefits associated with measuring whether employee performance improved through training investments. The participants explained that the success or failure of an organisation depends on the quality of training offered to employees. Training becomes an important element in the organisation if training procedures, standards and policies are followed as required. The organisation depends on the employee improved performance to achieve its objectives because employees play a significant role in the growth and innovation of the business.

Twelve participants $(100 \%)$ indicated that the organisation was benefitting from training interventions. Four participants $(33 \%)$ indicated that training and developing employees were crucial but were expensive investments and resources that were draining to the organisation. Participants indicated that it is, therefore, important to maximise the skills and knowledge of the trained employees in order to achieve the objectives of the organisation to sustain economic growth and maintain effective performance.

Subtheme 4.1: Return on investment through training evaluation: To determine whether training evaluation tools are used to assess the ROI, the participants responded that management was realising the importance of investing in 
training and development to improve business performance and productivity. It is the responsibility of HRD professionals and managers to evaluate whether there is monetary value in developing employees compared to the heavy cost of the training. Eight participants $(67 \%)$ indicated that training improves the availability and quality of employee output, which will, in turn, translate business performance into ROI. However, 11 participants (92\%) emphasised that training evaluation was not used to assess ROI because of the challenges associated with measuring and calculating the ROI of training interventions. The participant responses on ROI measurement are presented as follows:

'Managers are not committed and competent to assess the ROI.' (Participant 10, female, 40 years)

'Training assists in improving the Broad-Based Black Economic Employment (BBBEE) scorecard. BBBEE encourages organisations to develop previously disadvantaged population of South Africa including Black, Indian and Coloured. Most of the businesses are not willing to associate with companies that do not comply with BBBEE requirements.' (Participant 3, male, 45 years)

The participants indicated that it is very challenging to assess the ROI stage of training evaluation. Participants find it difficult and time-consuming to select the appropriate criteria, evaluation tool and formula to assess the ROI. The evidence indicates that the impact, business results and cost-benefit analysis or ROI of training intervention measurement will not be as strong as it could have been demonstrated or expected.

\section{Theme 5: Training evaluation improvement}

To determine how current training evaluation models or tools can be improved to ensure that HRD and training interventions improve performance, participants were asked whether they had other evaluation templates or tools to share with other managers in SA. The participants explained that most of the training programmes were predestined to fail, as training providers placed more emphasis on conducting the training programme than identifying or meeting the training needs. Participants emphasised that the first HRD evaluation phase should involve the collaboration of HRD professionals and managers to ascertain the correct organisational HRD needs, requirements and goals.

Employees need to understand their job requirements, and the link between training and their individual performance. Six participants $(50 \%)$ indicated that HRD professionals, performance managers and line managers should be able to assess the specific skills, capacities and competencies of employees, as well as identify and distinguish factors that hinder effective performance. Therefore, HRD professionals should establish precise, unbiased and realistic employee training needs whilst ensuring that employee performance improvement is critical and significant to achieving business results.

Subtheme 5.1: Mentoring and coaching to improve employee performance: Performance assessment timelines, nine participants $(75 \%)$ responded that managers should hold transparent, open skills needs discussions with individuals and teams. Discussion topics should include the following: awareness of business strategy; awareness of HRD strategy; how performance measurement will take place; what will be measured; what is expected from HRD interventions; HRD, mentoring and coaching goals and timelines; key performance areas and indicators (KPAs and KPIs); and equitable and fair rewards for improved performance.

Three participants $(25 \%)$ also indicated that performance reviews should be transparent, authentic and acceptable. This suggests that managers should have continuous discussion with individuals to understand whether the training interventions were valuable and if training objectives were met. Managers must also measure whether the current and future workforce is equipped to meet all HRD and business expectations. Participants' responses indicated that mentoring and coaching may be good HRD options as follows:

'Managers should ensure that feedback discussions take place regularly with accurate measures for improved performance or not.' (Participant 4, female, 55 years)

'Managers should have face-to-face coaching with employees on a regular basis to understand any employee challenges and intervene if there is a need to do so.' (Participant 9, female, 31 years)

\section{Discussion}

The primary aim of the study was to explore whether training evaluations revealed that employee performance improved after training interventions were implemented in South African financial organisations. Findings provided significant insight into whether employees are applying the acquired skills and knowledge on the job to improve their performance. Five significant themes and subthemes indicate that participants understand and utilise HRD and training evaluation tools to measure employee performance improvement. Significantly, training interventions are usually offered when employees are failing to meet the current work standards. Training evaluation tools are used to assess the success of training interventions. What is evident in this research is that participants confirmed that the success of training interventions should be evaluated and verified just as the success of the organisational strategic business objectives is. Ramiah (2014) agrees that effective training evaluation tools are required to ascertain if the organisation's money was well spent when employees personally benefit from training. Evaluation tools must measure whether trainees are imparting their newly acquired knowledge to their team members and improving their performance and business objectives.

This study significantly confirms that South African financial managers use the Kirkpatrick-Philips evaluation tool to assess whether technical skills and behaviours of their employees improved after training. Most participants (75\%) in the financial organisations use training evaluations to observe both the extent to which the employees are applying their training and whether there is performance improvement afterwards by conducting one-on-one discussions once or 
twice a year to discuss employee performance improvement. Employee ratings of their own behaviour and skills were accounted for in terms of learning and how they used the acquired knowledge and skills on the job. Chan (2016) indicated that training evaluation is vital in providing feedback on how training impacts performance. Findings, however, indicated that managers are not using the Kirkpatrick-evaluation tool consistently and that it not effective to evaluate performance once or twice a year. Performance managers and employees suggested that managers need to give regular performance feedback to employees to ensure that the skills, knowledge and behaviour acquired from the training intervention are being practiced. Their concerns align with Jasson and Govender (2017) who confirm that training evaluation in SA has been criticised as ineffective regardless of the choice of evaluation model, as it ignores ROI measurements.

Both performance managers and line managers indicated that they have performance management processes in place to monitor employee performance progress against their job objectives or goals. Performance management processes focus on identifying, measuring and dealing with employee performance gaps. The process enables, encourages, coordinates and supports employees to achieve their performance objectives. Managers in the South African financial organisations stated that performance evaluation is not an event; it is an ongoing process consisting of various activities and actions. Findings confirm that performance management systems should measure and analyse performance to determine training and development needs. Elnaga and Imran (2013) found that training and development bridge the gap between current performance and desired performance. Whilst this study found that there is a relationship between training and performance, performance managers were sceptical of the relationship between training and employee performance improvement because training evaluation tools are not being used effectively.

This study found that the success of the performance management system interrelates with the training efforts. Most training benefits are easily achieved when training is planned, implemented and evaluated correctly.
The significant themes and subthemes allowed for a practical training-performance framework to emerge from this study. Figure 1 presents the proposed training evaluation framework for performance improvement.

Figure 1 demonstrates the phases in the framework that HRD professionals and managers can move through as they navigate the assessment of the employee performance, training, evaluation and improvement processes. This framework will work effectively to improve employee performance if managers and employees can adhere and apply it to their daily activities.

The phases of the proposed training evaluation framework for improved performance are as follows:

1. Organisational strategy and objective: Strategy for positive transfer of training should begin before the training intervention. Organisations are in business to make profit and every business is under pressure to show how training contributes to business success or else it faces cost reduction and even outsourcing.

2. Departmental objectives and competencies plan: Training activities should help to achieve the business strategy. Therefore, each department must plan to integrate the business goal, training policies and actions.

3. Performance review and feedback: Managers must optimise employee performance and contribution towards meeting the organisational objectives and goals. Performance reviews allow managers and employees to analyse, examine and evaluate performance over a period. Managers need to provide performance feedback, identify individual strengths and weaknesses and identify training needs.

4. Training needs: Managers can use problem centred approaches (focuses on performance difficulties because of insufficient skills or knowledge) and profile comparison approaches (assesses person-organisation fit) to analyse training needs.

5. Training plan and intervention: Human resource development professionals and managers must identify the budget, time and expertise required for training. Although there are different training methods that can be implemented, the main purpose of training is to help employees learn so that they can perform their job successfully and innovatively.

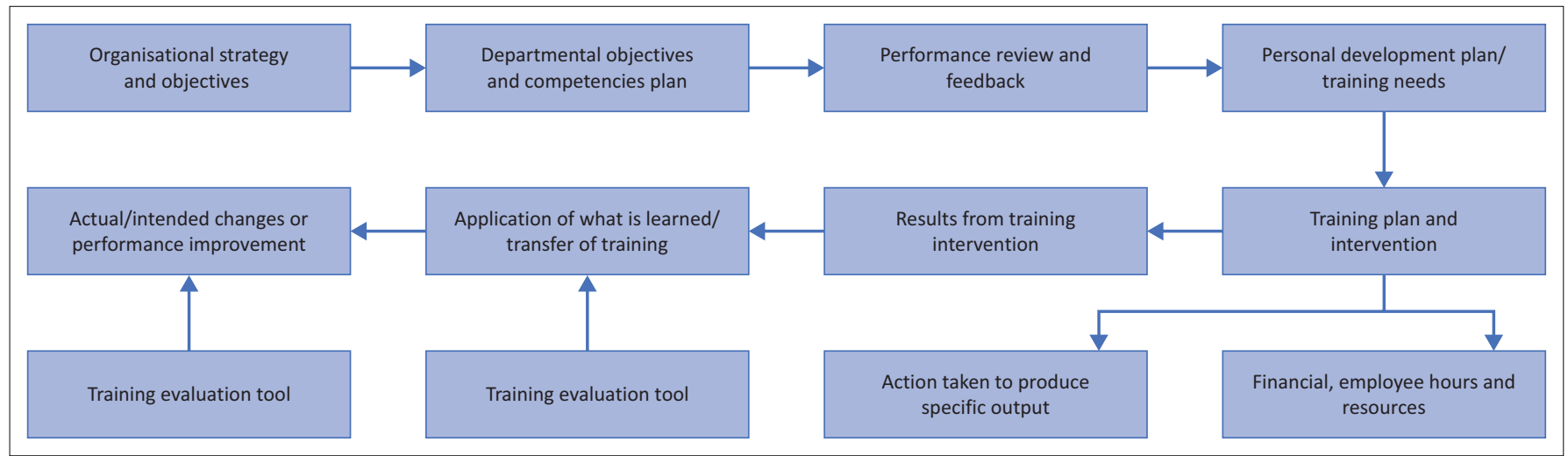

FIGURE 1: Proposed training evaluation framework for performance improvement. 
6. Results from training interventions: There are several activities a trainer can implement during training to facilitate the transfer of learning. Trainers must motivate learners by explaining the value of work skills and by using familiar examples. Learners must establish a plan of action for applying the new learning to improve performance.

7. Transfer of training: After training interventions, managers must ensure that employees have immediate and frequent opportunities to practice what they have learned. Managers must use the training evaluation tools frequently to assess performance improvement. Employees should be rewarded for using new skills on the job.

8. Performance improvement: Positive feedbacks from managers demonstrate support and create a positive transfer climate which leads to performance improvement.

\section{Limitations of the study}

The study was limited to two financial organisations in the Gauteng province of SA. A small convenient sample was used. Findings may not be similar for other financial organisations in different provinces, or for organisations in other sectors. A larger sample and adding participants from other organisations could have improved the scope of this study and the transferability of the findings.

\section{Conclusion}

The benefits of improving employee performance are lost when training and development intervention are not measured and managed well because of the complexities and challenges encountered during evaluation. Figure 1 encourages HRD professionals, performance managers and line managers to conduct training needs assessments, implement training, measure it and determine if performance improved after training. This article confirms that there is a relationship between training evaluation and employee performance improvement, despite the challenges with time, skills, complexities and resources to accurately measure the ROI of training. Further research is recommended to explore the following: whether managers are trained to evaluate business results and ROI; how coaching and mentoring encourage employees to apply learned skills, behaviours and knowledge after training interventions and whether the proposed training evaluation framework for performance improvement, as shown in Figure 1, is a viable model for managers to measure performance improvement using training evaluation tools within the SA financial sector.

\section{Acknowledgements Competing interests}

The authors have declared that no competing interest exists.

\section{Authors' contribution}

K.D.M., C.M.G and C.M.M. contributed to the design and implementation of the research, to the analysis of the results and to the writing of the manuscript.

\section{Funding information}

This research received no specific grant from any funding agency in the public, commercial or not-for-profit sectors.

\section{Data availability}

Data sharing is not applicable to this article as no new data were created or analysed in this study.

\section{Disclaimer}

The view and opinions expressed in this article are those of the author and do not necessarily reflect the official policy or position of any affiliated agency of the author.

\section{References}

Abrahams, M.A. (2015). A review of the growth of monitoring and evaluation in South Africa: Monitoring and evaluation as a profession, an industry and a governance tool. African Evaluation Journal, 3(1), 1-8. https://doi.org/10.4102/ aej.v3i1.142

Ahmed, Z., Rehman, Z.U., Asad, A., Hussain, N., \& Bilal, A. (2013). The impact of organisational change on the employee's performance in banking sector of Pakistan. Ethiopian International Journal of Multidisciplinary Research, 1(1), 1-12.

Almohaimmeed, B.M.A. (2017). Training and performance: A sign from Saudi service organization. International Business Research, 10(11), 147-157. https://doi. org/10.5539/ibr.v10n11p148

Aragón, M.B., Jiménez, D.J., \& Valle, R.S. (2014). Training and performance. The meditating role of organizational learning. Business Research Quarterly, 17(3), 161-173. https://doi.org/10.1016/j.cede.2013.05.003

Bernard, H.R. (2002). Research methods in anthropology: Qualitative and quantitative approaches (3rd edn.). Thousand Oaks, CA: Sage.

Blumberg, B.F., Cooper, D.R., \& Schindler, P.S. (2014). Business research methods (4th edn.). London: McGraw Hill Education.

Chan, K.C.M. (2016). A critical analysis of a program evaluation: A case study on the effectiveness of a teacher training program. Asian Journal of Educational Research, 4(5), 24-33.

Clarke, V., \& Braun, V. (2013). Teaching thematic analysis: Over-coming challenges and developing strategies for effective learning. The Psychologist, 26(2), 120-123.

Creswell, J.W. (2014). Research design: Qualitative, quantitative and mixed methods approaches (4th edn.). Los Angeles, CA: Sage.

Creswell, J.W., \& Creswell, J.D. (2018). Research design: Qualitative, quantitative and mixed methods approaches (5th edn.). Thousand Oaks, CA: Sage.

Curado, C., \& Teixeira, S.M. (2014). Training evaluation levels and ROI: The case of a small logistics company. European Journal of Training and Development, 38(9), 845-870. https://doi.org/10.1108/EJTD-05-2014-0037

Etikan, I., Musa, S.A., \& Alkassim, R.S. (2016). Comparison of convenience sampling and purposive sampling. American Journal of Theoretical and Applied Statistics, 5(1), 1-4. https://doi.org/10.11648/j.ajtas.20160501.11

Elnaga, A., \& Imran, A. (2013). The effect of training on employee performance. European Journal of Business and Management, 5(4), 137-147.

Gentles, S.J., Charles, C., Ploeg, J., \& McKibbon, K.A. (2015). Sampling in qualitative research: Insight from overview of the methods literature. The Qualitative Report, 20(11), 1772-1789.

Hailesilasie, G. (2009). Determinants of public employees' performance: Evidence from Ethiopian public organizations. International Journal of Productivity and Performance Management, 58(3), 238-253. https://doi.org/10.1108/ 17410400910938841

Hameed, A., \& Waheed, A. (2011). Employee development and its affect on employee performance - A conceptual framework. International Journal of Business and Social Science, 2(13), 224-229.

Imran, M., \& Tanveer, A. (2015). Impact of training and development on employees' performance in banks of Pakistan. European Journal of Training and Development Studies, 3(1), 22-44.

Jasson, C.C., \& Govender, C.M. (2017). Measuring return on investment and risk in training - A business training evaluation model for managers and leaders. Acto Commercii, 17(1), a401. https://doi.org/10.4102/ac.v17i1.401

Jesuthasan, R. (2013). Performance management as a business discipline. People and Strategy, 36(2), 58-71.

Khan, R.A.G., Khan, F.A., \& Khan, M.A. (2011). Impact of training and development on organizational performance. Global Journal of Management and Business Research, 11(7), 63-68.

Kirkpatrick, J.D., \& KirkPatrick, W.K. (2016). Kirkpatrick's four levels of training evaluation. Alexandria, VA: ATD Press. 
Mason, J. (2002). Qualitative researching (2nd edn.). Sage.

MburuMaina, P., \& Waithfaka, P. (2017). Effect of on-the-job training on performance of the Kenya police service. Journal of Business and Management, 19(9), 64-71.

Meyer, E., Opperman, C., \& Dyrbye, C. (2003). Measuring return on investment in training: Practical guidelines for implementation. Knowres Publishing.

Mouton, J. (2001). How to succeed in your masters and doctoral studies: A South African guide and resource book. Pretoria: Van Schaik.

O'Keeffe, J., Buytaert, W., Mijic, A., Brozovic, N., \& Sinha, R. (2016). The use of semistructured interviews for the characterisation of farmer irrigation practices. Hydrology and Earth System Sciences, 20(5), 1911-1924. https://doi.org/10.5194/ hess-20-1911-2016

Phillips, J., \& Phillips, P. (2009). Using ROI to demonstrate performance value in the public sector. Performance Improvement, 48(4), 22-28. https://doi.org/10.1002/ pfi.20066

Shaheen, A., Naqvi, S., \& Khan, M. (2013). Employees training and organizational performance: Meditation by employee performance. Interdisciplinary Journal of Contemporary Business Research, 5(4), 490-503.
Sharma, T., \& Kurukshetra, K.U. (2012). Management of training and development: Training process - An overview; role, responsibilities and challenges to training manager. Retrieved from http://ddegjust.ac.in

Short, T. (2009). Exploring the vacuum in training evaluation: Is this a case of mission impossible? Development and Learning in Organisations, 23(5), 15-18. https://doi. org/10.1108/14777280910982933

Shwerani, K., \& Mohammed, N. (2015). An analysis of training and employee performance: A case study in a telecommunication company in Erbil. International Journal of Social Sciences \& Educational Studies, 2(2), 74-82.

Tai, W. (2004). Effects of training framing, general self-efficacy and training motivation on trainee's training effectiveness. Personnel Review, 35(1), 51-65. https://doi. org/10.1108/00483480610636786

Thomas, E., \& Magilvy, J.K. (2011). Qualitative rigor or research validity in qualitative research. Journal for Specialists in Paediatric Nursing, 16(2), 151-155. https:// doi:10.1111/j.1744-6155.2011.00283.x

Tshukudu, T.T. \& Nel, D. (2015). Strategies for evaluating training and development initiatives in public sector setting. African Journal of Public Affairs, 8(3), 190-206.

Yusoff, M.A.M., Ahmad, J., Mansor, A.N., Johari, R., Othman, K., \& Hassan, N.C. (2016). Evaluation of school-based assessment teacher training programme. Creative Education, 7(4), 627-638. https://doi.org/10.4236/ce.2016.74065 